\title{
Q fever and leptospirosis in the dairy farming community and allied workers of Worcestershire
}

\author{
R. J. HENDERSON
}

From the Public Health Laboratory, Worcester

SYNOPSIS Sera collected from dairy farmers, their families and farm workers, slaughtermen, artificial inseminators, veterinarians, and a group of doctors and civil servants with no direct connexion with farming were examined for evidence of $Q$ fever or leptospirosis. One thousand and fifty-two sera examined for $Q$ fever yielded $26 \%$ of positive results with titres of complement-fixing antibody through 1 in 4 to 1 in 128 and over. On the other hand, 876 sera examined for agglutinating antibody to various leptospirae showed only $0.5 \%$ of positive titres of 1 in 80 and over. None of the individuals with positive sera for $Q$ fever had ever been ill with anything resembling $Q$ fever or could remember any ill health in the past; this suggests subclinical infection. One farmer with a high titre against $L$. copenhageni (icterohaemorrhagiae) gave a history of a recent febrile illness very suggestive of acute leptospirosis. Infection due to leptospirae appeared to be very much less common than that due to $C$. burneti.

During a survey of brucellosis among the dairy farming community and allied workers in Worcestershire in 1966-67 (Henderson, 1967) sera from the individuals interviewed and questioned about their health were also examined for evidence of $Q$ fever and leptospiral infection. For $Q$ fever, sera from the following groups were examined: dairy farmers, their families, and farm workers, 822; slaughtermen, 67 ; veterinarians, 50 ; meat inspectors, 35 ; artificial inseminators, 28; a group of doctors and civil servants, 50. After the $Q$ fever complement-fixation tests were completed enough of most of the serological samples remained to allow agglutination tests for leptospirosis to be done as follows: dairy farmers, their families, and farm workers, 728; slaughtermen, 55; veterinarians, 39 ; meat inspectors, 8; artificial inseminators, 23; doctors and civil servants, 23.

Each of those from whom blood was taken was interviewed personally and questioned closely about present and past health, absence from work due to sickness, and ill health of any kind, such as jaundice, A card was used during the interview so that appropriate questions were not forgotten, and although these were designed primarily to uncover any symptoms or physical signs that could have arisen from acute or chronic brucellosis, it was

Received for publication 13 January 1969. expected that any caused by infection with Coxiella burneti or leptospirae would also be brought to light.

METHODS

The sera were examined for $Q$ fever antibodies by the complement-fixation test employing the method recommended by Bradstreet and Taylor (1962). Over two-thirds of all sera were examined by the use of both phase 1 and phase 2 antigens. The remainder were examined using phase 2 antigen only. For leptospiral antibodies the sera were sent to laboratories experienced in this type of work.

\section{RESULTS}

FEVER No cases of acute $Q$ fever were seen during the survey nor did any person interviewed give a history suggestive of an attack of $Q$ fever in the past. However, $26.0 \%$ of all the sera examined were found to have titres against phase 2 antigen ranging from 1 in 4 to 1 in 128 or over, and, taking into account a total absence of illness, this percentage represents a high incidence of subclinical infection. Table I shows how the different groups were affected. Table II gives a breakdown of the farmers, their families, and farm workers, for sex as well as for age.

The results show that Q-fever-positive sera were distributed among all groups, the highest proportion 
TABLE I

SERA POSITIVE BY THE COMPLEMENT-FIXATION TEST FOR Q FEVER ANTIBODIES AMONG DAIRY FARMERS, THEIR FAMILIES, AND FARM AND ALLIED WORKERS BY AGE GROUP

\begin{tabular}{|c|c|c|c|c|c|}
\hline \multirow[b]{2}{*}{ Category } & \multicolumn{5}{|c|}{ Number Positive/No. Examined } \\
\hline & $0-20$ Years & $21-40$ Years & 41-60 Years & Over 60 Years & $\begin{array}{l}\text { Total No. } \\
\text { Positive }\end{array}$ \\
\hline Farmers, their families, and farm workers & $\begin{array}{l}29 / 141 \\
(20 \cdot 5)^{1}\end{array}$ & $\begin{array}{l}63 / 286 \\
(22 \cdot 0)\end{array}$ & $\begin{array}{l}90 / 284 \\
(31 \cdot 6)\end{array}$ & $\begin{array}{l}21 / 111 \\
(18 \cdot 9)\end{array}$ & $\begin{array}{l}203 / 822 \\
(24 \cdot 6)\end{array}$ \\
\hline Veterinarians & $0 / 0$ & $\begin{array}{l}10 / 30 \\
(33 \cdot 3)\end{array}$ & $\begin{array}{l}8 / 18 \\
(44 \cdot 4)\end{array}$ & $\begin{array}{l}1 / 2 \\
(50)\end{array}$ & $\begin{array}{l}19 / 50 \\
(38)\end{array}$ \\
\hline Slaughtermen & $\begin{array}{l}6 / 20 \\
(30)\end{array}$ & $\begin{array}{l}13 / 31 \\
(42 \cdot 5)\end{array}$ & $\begin{array}{l}3 / 14 \\
(21 \cdot 3)\end{array}$ & $\begin{array}{l}1 / 2 \\
(50)\end{array}$ & $\begin{array}{l}23 / 67 \\
(34 \cdot 3)\end{array}$ \\
\hline Artificial inseminators & $0 / 0$ & $\begin{array}{l}8 / 16 \\
(50)\end{array}$ & $\begin{array}{l}2 / 12 \\
(16 \cdot 6)\end{array}$ & $0 / 0$ & $\begin{array}{l}10 / 28 \\
(35 \cdot 7)\end{array}$ \\
\hline Meat inspectors & $0 / 0$ & $\begin{array}{l}5 / 20 \\
(25 \cdot 1)\end{array}$ & $\begin{array}{l}4 / 13 \\
(30 \cdot 1)\end{array}$ & $0 / 2$ & $\begin{array}{l}9 / 35 \\
(25 \cdot 7)\end{array}$ \\
\hline Doctors and civil servants & $0 / 0$ & $\begin{array}{l}5 / 27 \\
(18 \cdot 5)\end{array}$ & $\begin{array}{l}3 / 21 \\
(14 \cdot 2)\end{array}$ & $\begin{array}{l}1 / 2 \\
(50)\end{array}$ & $\begin{array}{l}9 / 50 \\
(18) \\
273 / 1052 \\
(25 \cdot 9)\end{array}$ \\
\hline
\end{tabular}

'Figures in brackets are percentages.

TABLE II

SERA POSITIVE BY THE COMPLEMENT-FIXATION TEST FOR Q FEVER ANTIBODIES AMONG DAIRY FARMERS, THEIR FAMILIES, AND FARM WORKERS BY AGE AND SEX

Grouped by Age (yr)

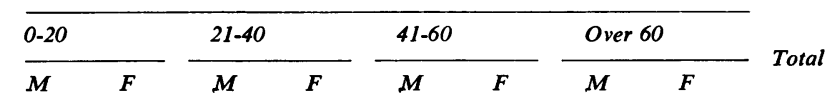

No. of farm personnel by age and sex

No. positive

Percentage positive

Minimum titre rated as significant $=1$ in 4 .

$\begin{array}{lcccccccc}95 & 46 & 186 & 100 & 163 & 121 & 67 & 44 & 822 \\ 23 & 6 & 44 & 19 & 54 & 36 & 16 & 5 & 203 \\ 24 \cdot 2 & 13 \cdot 0 & 21 \cdot 4 & 19 \cdot 0 & 33 \cdot 1 & 21 \cdot 4 & 23 \cdot 8 & 11 \cdot 3 & 24 \cdot 6\end{array}$

of positive sera being among veterinarians and the lowest among doctors and civil servants.

There were 54 farms where only one person on each had a positive serum. Fifty-seven other farms yielded 149 positive sera among them. On one farm six of seven persons had positive sera for $Q$ fever, $i e$, titres of 1 in 4 or greater.

LEPTOSPIROSIS One farmer had a febrile illness three months previously which lasted approximately two weeks. He had had a dry tongue, sweating, and malaise. There had been no glandular involvement and the Paul Bunnell test was negative. His serum gave a titre of 1 in 5,120 for $L$. copenhageni, ie, three months after the onset of illness. Otherwise no illness past or present was recorded for any other person. Another farmer had a titre of 1 in 100 for $L$. copenhageni, another a titre of 1 in 100 against each of $L$. sarmin and $L$. ndambari, a third had a titre of 1 in 80 against $L$. canicola, and a fourth a titre of 1 in 80 against $L$. copenhageni. Low titres, 1 in 10 to 1 in 30 , were found in the sera of 13 veterinarians, one slaughterman, one doctor, and 49 farmers against 24 different strains of leptospirae, eg, L. andamana, L. semaranga, L. bratislava, $L$ ballum, L. sejroe, L. poi.

\section{DISCUSSION}

The epidemiology of $\mathbf{Q}$ fever in Great Britain has? been studied fully by Marmion and Stoker (1958) who state that the disease is widespread, that sheep? or cattle are directly or indirectly the main sourceso of infection, and that untreated milk is a vehicle of infection. In south Worcestershire, however, theo acute form of the disease is rare and during the pase. 15 years only five acute cases were recorded. Theseos were all in people associated in some way or othen with animal husbandry-an agricultural salesmans a butcher, a dairy farmer, an electricity linesman accustomed to working on farms, and a garage manager who lived beside a farm. Marmion and Stoker observed that the consumption of infected? milk appeared at the most to be responsible for only sporadic cases and offered as an explanation for the infrequency of acute illness 'resistance in some way of the nasopharynx and intestinal tract. He also suggested that a 'protective or neutralizing property? 
of whey antibody in infected milk produces antibodycoated rickettsiae' which might lead to subclinical rather than clinical infection.

A suggestion offered here and prompted by the finding of $26 \%$ of positive sera among farmers, their families, and allied workers is that there is, in fact, widespread infection by $C$. burneti among these people. The organism, however, although highly infectious, is of low pathogenicity and this leads to subclinical rather than overt clinical infection. The picture is much the same as that seen in the dairy farming community when the infecting bacterium is Brucella abortus, that is, few acute cases and many subclinical infections (Wilson and Miles, 1955, Henderson, 1967).

Since two, three, or even more persons on each of $\mathbf{5 7}$ farms were found to have positive sera though they were not necessarily working with or in very close contact with cattle it would be reasonable to suppose that they were probably infected by drinking untreated milk; nevertheless the number of positive sera among veterinarians (38\%), slaughtermen $34.3 \%$ ), and artificial inseminators (35.7\%) shows that infection is not always by this means. It is more probable that these groups become infected by contact through the skin or by the inhalation of coxiellae in infected dust or aerosols in farm premises or slaughter houses.

The group of doctors and civil servants was originally chosen as a control group for the brucellosis part of the survey because it was felt that their contact with $B$. abortus would be very slight, if at all; none of them lived on farms or had drunk untreated milk for at least 10 years. As it turned out they did not form a very satisfactory control group for $Q$ fever. Though it was shown that they were not exposed to $B$. abortus it is clear from the $18 \%$ of positive sera that they must have been in contact with $C$. burneti. Inquiry in fact revealed that the nine members of the group with serological evidence of infection with $C$. burneti lived on the outskirts of the city, in what were virtually rural surroundings. Six of the nine were keen gardeners. Worcester is in the midst of an agricultural area and the fields of many dairy farms extend among the houses on the outskirts of the city. For example, five members of the group lived in houses surrounded by fields in which cattle grazed and with farm buildings between 200 and 300 yards distant. Thus they could have been exposed to rickettsia-infected dust. Infection could also have come from treated milk, since pasteurization is said not to kill all rickettsiae in heavily infected milk, or from consuming fresh cream.

It is worth mentioning in this connexion that the only fact that seemed to have relevance in the medical history of one of the acute cases of the disease (agricultural salesman) was that the patient had turned over a large compost heap in his own garden two weeks before the onset of illness; otherwise he had not visited a farm or exposed himself to any obvious source of infection during the incubation period.

With regard to studies of $Q$ fever by others in Britain, Grist (1956) found very little evidence of human $\mathbf{Q}$ fever, clinical or subclinical, in Glasgow or south-west Scotland. Studies in animals revealed a minor degree of infection in cattle in Perthshire, Stirlingshire, and Lanarkshire but none in southwest Scotland or other areas. There seems to be more infection in England; Slavin (1952) found evidence of infection in approximately $6.9 \%$ of dairy farms in England. Marmion, Stoker, McCoy, Malloch, and Moore (1953) showed that $C$. burneti was present in milk from $8.2 \%$ of herds in Kent, $2.7 \%$ in Devon, and $0.85 \%$ in East Anglia.

It has been suggested by Marmion, Higgins, Bridges, and Edwards (1960) that the presence of phase 1 complement-fixing antibody may be a useful indicator of the presence of chronic $Q$ fever. Both phase 1 and phase 2 antigen were used to examine most sera in this survey; usually when sera were positive they were positive to phase 2 antigen and negative to phase 1 . Nineteen sera, however, were positive with both phase 1 and phase 2 ; there was no indication that any of the 19 was suffering from chronic $Q$ fever. One serum was positive with phase 1 and negative with phase 2 . There was no evidence of chronic disease in this individual either.

The results of the examination of sera for leptospiral antibodies suggest a different situation from that of $\mathbf{Q}$ fever or brucellosis. The high titre for $L$. copenhageni in one farmer fitted well with the history of an undiagnosed febrile illness three months previously. The other four titres of between 1 in 80 and 1 in 100 may have been due to subclinical infection. This would give a rate in 876 sera of $0.1 \%$ for acute and $0.45 \%$ for subclinical infections. Wilson (1966), examining 335 sera sent from patients in Northern Ireland to his laboratory for a variety of tests, was able to make a diagnosis of acute leptospirosis in seven patients $(2 \%)$ and of infection in the past in nine others $(2.7 \%)$. Wilson used 1 in 100 as the lowest diagnostic titre. The circumstances, however, are not strictly comparable. In the north of Ireland study, the sera were all from people who were or had been ill. In this study, with the exception of one farmer who had had an illness three months previously, no other person gave a history of previous illness.

More comparable studies perhaps are those by Smith and Davidson who investigated leptospirosis 
in fish workers in Aberdeen. They collected information about 46 acute cases of the disease (Davidson and Smith, 1936) and then went on to examine the sera of 210 fish workers (Smith and Davidson, 1936) who were in good health at the time of examination.

Of the 210,33 either had a history of a febrile disease with jaundice in the past, or a history of some other febrile illness such as 'influenza' or 'sore throat with malaise'. One hundred and seventy-seven gave no history of illness of any kind, and of these 18 $(10.1 \%)$ had sero-positive reactions ranging from 1 in 30 to 1 in 1,000 . It would appear that the incidence of disease, acute and subclinical, was high among the fish workers of Aberdeen compared with patients drawn from the general population of Northern Ireland or the dairy farming community of Worcestershire. Buchanan (1927), reporting cases of acute leptospirosis among coal miners of East Lothian, collected details of 22 acute cases in 1927. No serological studies, however, were carried out among the coal miners.

An interesting point arises about the minimum titre of serological reaction against leptospirae that could be regarded as of diagnostic value. Titres of 1 in 10 to 1 in 30 were found in the sera of 49 farmers, 13 veterinarians, one doctor, and one slaughterman against 24 different strains of leptospirae. The question is whether these titres are significant. With regard to the reactions of the veterinarians, it is worth mentioning that two sera reacted with $L$. sejroe at 1 in 30 and two others with $L$. castelloni and $L$. ballum at 1 in 10 each. Each of these strains has been isolated from field mice and voles in this country and theoretically, therefore, infection could be possible. On the other hand one of the sera reacted with $L$. butembo, a Congolese strain which so far does not appear to have been isolated elsewhere than in the Congo. It is possible that the suspensions were too sensitive and, therefore, titres of 1 in 10 to 1 in 30 could be ignored.

With regard to the farmers, there were 49 sera with low titres of 1 in 10 to 1 in 30 against various leptospirae. As in the case of the veterinarians one is tempted to think that these low titres could be ignored. However, there were six farms on each of which two persons reacted, albeit with low titres, to the same strain of leptospira. The strain $\overrightarrow{0 \overrightarrow{6}}$ course was not the same for all six farms. The faet of two people living on the same farm showin reactions to the same strain prompts one to think that these were the result of infection. Yet these were only 12 sera of 728 , a small proportion.

It has been suggested elsewhere that Q-fever? positive sera are apt to give false positive reaction $\$$ against leptospirae. This hypothesis was tested. Seventeen sera, all of which had titres against burneti of from 1 in 64 to 1 in 512, were examineक With the exception of two which reacted against poi and $L$. erinacei-auriti at a titre of 1 in 10 the remainder were negative.

It would seem that there is great similarity between brucellosis and $\mathrm{Q}$ fever. Brucella abortus and $C$. burneti are possibly organisms of low pathogenicity leading to widespread subclinical infection rather than overt clinical disease. Leptospiral infee $\mathbb{D}$ tion, however, is in quite a different categorgo Whereas infection may be subclinical it is rare seen in dairy farmers or their families or in allied occupational groups; in fact the incidence is pose sibly no more than that in the general populatiore

I have to thank Dr W. L. Hooper of the Public Health Laboratory, Stafford, and Dr L. H. Turner, of the Leptospirosis Reference Laboratory, London School of Hygiene and Tropical Medicine, for carrying out the leptospiral serological tests.

\section{REFERENCES}

Bradstreet, C. M. P., and Taylor, C. E. D. (1962). Mth. Bull. Minișt Hlth. Lab. Serv., 21, 96.

Buchanan, G. (1927). Spec. Rep. Ser. med. Res. Coun. (Lond.), 113 Davidson, L. S. P., and Smith, J. (1936). Quart. J. Med., 5, 263.

Grist, N. R. (1956). Scot. med. J., 1, 173.

Henderson, R. J. (1967). Lancet, 2, 353.

Marmion, B. P., Stoker, M. G. P., McCoy J. H. Malloch, R. A and Moore, B. (1953). Lancet, 1, 503. (1958). Brit. med. J., 2, 809.

, Higgins, F. E., Bridges, J. B., and Edwards, A. T. (1960) Ibid, 2, 1264

Slavin, G. (1952). Vet. Rec., 64, 743.

Smith, J., and Davidson, L. S. P. (1936). J. Hygiene, 36, 438.

Wilson, G. S., and Miles, A. A. (1955). In Topley and Wilsors Principles of Bacteriology amd Immunity, 4th ed. Arnole London.

Wilson, T. S. (1966). J. clin. Path., 19, 415 